\title{
Dimensions of Social Intelligence of Adolescents
}

\author{
Reena, Bimla dhanda** and Pinki ninaniya* \\ Department of Human Development and Family StudiesI. C. College of Home Sciences \\ CCSHAU, Hisar -125004Haryana, India
}

\begin{abstract}
The present study was carried out on 300 adolescents from Panipat district of Haryana state. Social intelligence scale by Chadda and Ganeshan (1986) was used to assess the social intelligence of adolescents. Results revealed that there significant variation $\left(\mathrm{F}=5.0^{* *}\right)$ for social intelligence in their bolcks. . It was observed that significance difference across social intelligence blocks panipat and smalkha $(\mathrm{Z}=3.1 * *)$, bapoli and smalkha $(\mathrm{Z}=1.9 *)$.
\end{abstract}

KEY WORDS: Social intelligence, Adolescents and Blocks

\section{INTRODUCTION}

Social intelligence helps to maintain a state of harmony in oneself and finally motivate to deal with the challenges in educational institutions (Saxena and Jain, 2013). Social intelligence is defined as awareness of the motivations of self and others and the ability to flourish in social situations (Park and Peterson, 2006; Peterson and Seligman, 2004). Social intelligence appears to be one of the important psychological abilities that relate to success in life as an students low on social- emotional intelligence face more difficulties to deal with others which undermines their academic motivation (Drago, 2004). Children born into socioeconomically disadvantaged circumstances, particularly single-parent homes, are less likely to benefit from the kinds of parental attention, activities, and resources that stimulate soft skills (McLanahan, 2004).

\section{RESEARCH METHODS}

Present study was conducted purposively at rural government schools of the district Panipat of state Haryana. These adolescents were selected from six government schools from three Block were taken randomly. From Bapoli block-1, two villages namely Ujha and Dadola were selected. From Smalkha block-2 two villages Rishlapur and Bapoli were selected. From panipat block -3 two villages Rishalu and Ugrakhari were selected. A sample of 300 hundred students studying in the age group of 13-14 years and studying in the $8^{\text {th }}$ grade. Social intelligence scale by Chadda and Ganeshan (1986) was used to assess the social intelligence of adolescents.

\section{RESEARCH FINDINGS AND DISCUSSION}

Analysis of variance for social intelligence in three blocks

The analysis of variance was computed to see the influence of cultural background of three blocks on way of motivating the students. The results supported by Uma and Uma (2005) studied socio-emotional intelligence of adolescents between the age range of 15-17 years and found that age was not significantly correlated with EI of the adolescents. The results showed that there significant variation $\left(\mathrm{F}=5.0^{* *}\right)$ for social intelligence in there bolcks. It was observed that significance difference across social intelligence blocks panipat and smalkha $(\mathrm{Z}$ $\left.=3.1^{* *}\right)$, bapoli and smalkha $\left(Z=1.9^{*}\right)$. Significant difference was found of social intelligence across village Ugrakhari, Rishalu, Dadola, Ujha, Bapoli and Rasahlapur. Gakhar and Bains (2009) supported the results through their research out comes which indicated the difference in social intelligent scores of students of different streams.

Table: 1 Analysis of variance for cultural differences on social intelligence

\begin{tabular}{|l|c|c|c|c|}
\hline Source of variation & DF & SS & MS & F value \\
\hline Between blocks & 2 & 319.8 & 159.9 & \multirow{2}{*}{$5.0^{* *}$} \\
\hline Within blocks & 297 & 9422.0 & 31.7 & \\
\hline Total & 299 & 9741.8 & & \\
\hline
\end{tabular}

Table: 2 Comparison of social intelligence in three blocks

\begin{tabular}{|c|c|c|c|c|}
\hline Blocks & Mean value & Mean difference & SE & Z- value \\
\hline Panipat and Bapoli & $85.5 \pm 5.9$ & 0.9 & 0.78 & 1.2 \\
\hline Panipat and smalkha & $86.2 \pm 5.5$ & 2.5 & 0.78 & $3.1^{* *}$ \\
\hline Bapoli and smalkha & $86.7 \pm 5.5$ & 1.5 & 0.78 & $1.9^{*}$ \\
\hline
\end{tabular}


$* *$ significant at $1 \%$ level of significance

\section{REFERENCES}

[1] Drago, J. M. 2004. The relationship between emotional intelligence and academic achievement in nontraditional college students. Doctoral Dissertation, Walden University.

[2] Gakhar, S.C. and Bains, 2009. A study of social intelligence and achievement motivation of students of arts and science stream. Journal of Educational Studies, 7(2) 56-59.

[3] Mclanahan 2004. Diverging destinies :how children are faring under the second demographic transition. Demography, 41(4) 607-27

[4] Park, N., \& Peterson, C. 2006. Moral competence and character strengths among adolescents: The development and validation of the values in action inventory of strengths for Youth. Journal of Adolescence.

[5] Saxena S. and Jain K. R. 2013. Social intelligence of undergraduate students in relation to their gender and subject stream. Journal of Research and Method in Education. 1:1-4.

[6] Uma, L., Uma, D. 2005. Relationship between the dimensions of emotional intelligence of adolescents and selected personal social variables. Indian Psychological review. 64(1) 11-20. 